\title{
Investigating Area and Volume Instruction for Prospective Teachers: A Lesson Experiment
}

\author{
Michelle Chamberlin, Megan Schnorenberg Candelaria
}

\begin{abstract}
A lesson experiment was used to investigate how instruction impacted prospective elementary teachers' conceptual understandings of area and volume. Data sources included ten prospective teachers' work on a measurement pre-assessment, lesson activities, and three postassessments as well as audio recordings of lesson activities. The qualitative analysis consisted of two steps: a 'real-time' analysis within the constraints of the week surrounding the lesson and an intensivedelayed' constant-comparative analysis over the next several months. Findings revealed the prospective teachers enhanced their understandings of area and volume. The lesson experiment led to instructional recommendations for improving the lesson in the future, such as the need to address prospective teachers' formulaic tendencies, interpretations about basic units, and perceptions of area and volume measurements as linear quantities. Implications include the value of lesson experiments as an iterative process to contribute to the shared knowledge base of mathematics teacher educators.
\end{abstract}

Keywords: Lesson Experiment, Prospective Teachers, Mathematics, Area, Volume, Qualitative Research

\section{INTRODUCTION}

The mathematical preparation of teachers has been a renewed topic of national attention in the United States. Mathematics Teaching Today (National Council of Teachers of Mathematics [NCTM], 2007) states teachers need to "have broad and deep knowledge of mathematical content, processes, and contexts" (p. 119). Similarly, several sources call for teachers to possess "mathematical knowledge for teaching" (e.g., Delaney, Ball, Hill, Schilling, \& Zopf, 2008; National Mathematics Advisory Panel, 2008). Such calls have only been heightened with the nearly nationwide state adoption of the Common Core State Standards (National Governors Association Center for Best Practices \& Council of Chief State School Officers, 2010). Thus, there is little disagreement that teachers need a robust knowledge of mathematics for teaching. However, the more challenging aspect of this need is "In what ways do the content-learning experiences in your teacher-preparation ... program help develop the robust and connected mathematical understandings needed for teaching?" (NCTM, 2007, p. 197). The objective of this study is to investigate how instruction impacts the mathematical understandings of prospective elementary teachers enrolled in a mathematics content course. We chose to examine prospective teachers' 
mathematical understandings of area and volume and how those understandings were impacted by an associated lesson. Specifically, the research questions are:

1. What are prospective elementary teachers' mathematical understandings of area and volume before, during, and after an associated lesson?

2. How does the lesson impact the prospective teachers' understandings of area and volume?

3. How might the lesson be enhanced within the class and for future class offerings?

\section{Mathematics Content Courses for Prospective Elementary Teachers}

Many policy reports detail the type and depth of mathematics content instruction prospective elementary teachers should receive (e.g., Conference Board of the Mathematical Sciences [CBMS], 2001; National Commission on Mathematics and Science Teaching for the Twenty-First Century [NCMST], 2000; NCTM, 2007; National Research Council [NRC], 2001). Future teachers need to have a deep understanding of the content they will teach in addition to an ability to apply that knowledge within classroom situations. Because of this, most reports encourage mathematics courses for prospective teachers be taught in a manner recommended for elementary classrooms. Courses for prospective teachers should use less lecturing, focus on small and whole group interaction, incorporate manipulatives and technology when appropriate, and foster a culture of inquiry-based learning (Lester et al., 1992; Libeskind, 2011; McLeod \& Huinker, 2007; NCMST, 2000). CBMS (2001) builds on this idea, recommending classroom experiences for prospective teachers which focus on the teachers' ideas for solving problems, affirm their use of sound reasoning, and challenge misconceptions in a non-hostile and learner-friendly environment. Finally, nearly all recommendations include an emphasis on the development of mathematical justification or reasoning, both as a method for developing deep mathematical knowledge and as a means for evaluating future students' understandings (CBMS, 2001; Lester, et al., 1992; Mcleod \& Huinker, 2007; Mewborn, 2001; NCMST 2000; NCTM, 2007).

With regard to examining the impact of such mathematics content courses for prospective elementary teachers, most research investigates the changes in their attitudes, beliefs, and perspectives regarding mathematics (Hart, 2002; Lubinski \& Otto, 2004; Matthews \& Seaman, 2007; Mizell \& Cates, 2004; Quinn \& Jadav, 1997). These studies detail the positive impacts possible within these domains. Other research examines how content courses impact prospective teachers' mathematical content knowledge, usually through a before-and-after evaluation, which again highlight potential benefits (Buck, 2004; Clarke, 1997; Matthews, Rech, \& Grandgenett, 2010; Matthews \& Seaman, 2007; Mcleod \& Huinker, 2007). However, these studies do not necessarily relate how or why instruction might have had an impact, illustrating a need for more research in this regard.

\section{Prospective Elementary Teachers' Understandings of Area and Volume}

The topic of area is prevalent, both in elementary school curriculums as well as in realworld applications. However, despite the concept's predominance, area is one of the lessunderstood topics of measurement (Murphy, 2012). While researchers have examined elementary students' understandings of area, less attention has been paid to those of elementary teachers. The research that has been done indicates that elementary teachers, both prospective and practicing, have many of the same misconceptions as those found in the students they teach. Woodward and Byrd (1983) demonstrated that the relationship between area and perimeter is challenging for both students and teachers. Reinke (1997) explained that this may be due to a lack of distinction between linear and square units on the part of prospective teachers. Researchers have also found that elementary teachers may equate area with length $x$ width or other formulas for common shapes, showing little to no understanding of area as coverage with a unit (Baturo \& Nason, 1996; Enochs \& Gabels, 1984; Tierney, Boyd, \& Davis, 1990). Teachers often have a very procedural-based 
understanding of area, thinking of it as a series of actions, a set of procedures, or a group of formulas (Berenson et al., 1997). Teachers who might wish to teach the topic conceptually may not be able to due to their low substantive knowledge (Baturo \& Nason, 1996; Berenson et al., 1997).

Similarly, for volume, prospective and practicing teachers have been found to pay more attention to linear measurements rather than thinking about volume as a threedimensional whole (Zevenbergen, 2005). Again, they may over-generalize volume as length $x$ width $x$ height, or they may fail to recognize that certain objects, such as a piece of paper in which one dimension is quite small, have a volume at all (Saiz, 2003). As with area, teachers may struggle to identify key concepts and processes involved in working with volume (O'Keefe \& Bobis, 2008). In particular, prospective teachers often fail to see any connection between the measuring done in a classroom and the 'real world' (Baturo \& Nason, 1996).

Some researchers have examined the impact of content courses on prospective teachers' mathematical understandings of area or volume, yet little research has been done on how the instruction impacts that understanding. Enochs and Gabel (1984) state that their research does not indicate how volume and area should be taught, but merely reveals that knowledge of the topics should not be treated as self-evident for prospective teachers. Other studies have indicated that content courses may raise prospective teachers' knowledge of area and volume (Senk, Demir, Park, \& Crespo, 2009). However, most research focuses on the misconceptions prospective teachers have in regard to area and volume or whether instruction righted those misconceptions. The purpose of this research is to gain insight into how instruction impacts prospective elementary teachers' understandings of area and volume.

\section{METHOD}

The focus of this study was a 3-credit geometry and measurement course for prospective elementary teachers. The course utilized Reconceptualizing Mathematics for Elementary School Teachers (Sowder, Sowder, \& Nickerson, 2009) and had three emphases: measurement, 2- and 3-dimensional shapes, and symmetry and congruence. The second author was the instructor, while both the first and second authors served as researchers for the study. The course included two in-class exams, a cumulative final exam, formative assessments, homework assignments, quizzes, a group project, and various writing prompts. All 19 prospective teachers in the course were elementary education majors with $63 \%$ sophomores, $26 \%$ juniors, and $11 \%$ seniors or post-baccalaureates. Prospective teachers self-identified their mathematical backgrounds as ranging from high school algebra to calculus.

\section{Research Design}

To examine the impact of the instruction on the prospective teachers' mathematical understandings, a lesson experiment was utilized. The purpose of a lesson experiment is to engage in cycles of creating and testing hypotheses about cause-effect relationships between teaching and learning during a classroom lesson (Hiebert, Morris, Berk, \& Jansen, 2007; Hiebert, Morris, \& Glass, 2003). It is a systematic process that focuses on the question, "What did students learn, and how and why did instruction influence such learning?" (Hiebert et al., 2007, p. 48). It is composed of four steps somewhat akin to teacher as researcher, reflective practice, and disciplined inquiry. The first step is explicating the learning goals for the students, which allows one to investigate whether and how the instruction helped the students achieve the desired goals. The second step is assessing whether and to what extent the learning goals are achieved during the lesson by gathering data on students' thinking from videos, transcripts, or students' written work. The third step consists of developing hypotheses for why the lesson did or did not achieve 
the learning goals. The fourth step entails using the hypotheses to revise the current or future lessons. In conducting a lesson experiment, such steps are not necessarily performed in a distinct sequential fashion, although the order provides a general framework for progression. This approach provides a shift of focus from teaching in the moment to including preparation and reflection outside the classroom, a promising response to the gap between research and practice. While Hiebert and his colleagues foremost recommend lesson experiments as a way to help teachers learn from teaching, they also recommend the approach for teacher educators.

\section{Area and Volume Lesson Experiment}

The lesson experiment took place the third week of the semester. Table 1 provides the learning goals for the lesson (Wiggins \& McTighe, 2005).

Table 1. Learning Objectives for Area and Volume Lesson

\section{Knowledge (K)}

K1: Area is the number of square units that cover a region.

K2: Volume is the number of cubic units (solid or liquid) that fill a space.

K3: Without a consistent unit, an attribute has different measures. Small units lead to larger measurements and vice versa.

K4: In learning to measure, elementary students are supported by a progression of a.) learning to perceive an attribute, b.) comparing objects with the same attribute, c.) measuring with a unit (nonstandard and then standard), and d.) working within a standard measurement system.

Skills (S)
S1: Compare, order, and
measure area and volume using
nonstandard and standard units
(including selecting an
appropriate unit or tool).
S2: Develop familiarity with
standard units for area and
volume (metric and English).

At the beginning of the course, prospective teachers completed a pre-assessment in which they explained area and volume as well as matched various objects with appropriate measures and units. The pre-assessments revealed that some prospective teachers held developing understandings in area while others in volume. Thus, due to class time constraints, the prospective teachers completed activities in either area or volume. The lesson began with the instructor proceeding through the Plan for Measurement Instruction (see Figure 1), which describes an instructional sequence recommended for supporting elementary students in learning about measurement (Inskeep, 1976; Van de Walle \& Lovin, 2006).

\section{Plan for Measurement Instruction}

Adapted from Van de Walle, J. A., \& Lovin, L. H. (2006). Teaching student-centered mathematics: Grades K-3. Boston, MA: Pearson.

- Goal 1: Students will understand the attribute to be measured.

○ Type of activity: Have students make comparisons of the attribute with different objects. For example: Which is longer/shorter? Heavier/Lighter? Holds more/Less? Use direct comparisons whenever possible, e.g., have the physical objects available for students to compare side by side.

○ Comment: Students need to understand the attribute to be measured; otherwise any measurement activities will have no meaning for them.

- Goal 2: Students will use units to produce a number called a measure.

○ Type of activity: Have students measure physical models of the attribute using nonstandard units. For example, using square sticky notes to measure (cover) the area of a two-dimensional shape. Include activities where students have multiple copies of the unit available and where students have only one copy of the unit available.

- Comment: The teacher can help students appreciate the need for a unit by asking them to measure objects that cannot be placed side by side or by asking them to communicate the measure to someone that cannot access the object.

- Comment: The teacher can help students understand the need for a common unit by asking them to measure a single object with different sized units - students will likely recognize the dilemma in determining different measures for the same object.

- Goal 3: Students will use common measuring tools, measurement systems, and formulas with understanding and flexibility.

- Type of activity: Have students make their own measuring instruments with informal units and then compare how those are measuring in the same way that standard instruments do (e.g., comparing waxed 
paper protractor with traditional protractor); allow students to measure physical objects with the standard units; plan activities for students to develop familiarity with standard units (e.g., treasure hunts, guess the unit).

- Comment: Introduce measurement formulas and unit conversions only after students fully understand how to directly measure the attribute.

Figure 1. Plan for Measurement Instruction introduced to the prospective teachers through an interactive lesson at the beginning of the area and volume lesson.

Next, prospective teachers completed either the volume or the area station (see Figures 2 and 3). Each station led prospective teachers through the Plan for Measurement Instruction. Specifically, for the volume station, the first step was to compare the volume of three cylinders, each formed from a standard sheet of paper but taped together in different ways. Second, the prospective teachers measured one of these cylinders with a nonstandard unit and then compared their measurement with another group (who, unbeknownst to either group, was measuring the same sized cylinder, but with a different sized non-standard unit.) The third step was to measure the volume of a cylinder using 1 $\mathrm{cm}$ by $1 \mathrm{~cm}$ by $1 \mathrm{~cm}$ base-ten blocks to emphasize the advantages of a standard unit. Finally, prospective teachers filled a hollow base-ten cube with water to illustrate that $1 \mathrm{~L}$ is equivalent to $1 \mathrm{dm}^{3}$ and that $1 \mathrm{~mL}$ is equivalent to the volume of $1 \mathrm{~cm}^{3}$. The area station presented a similar progression, first comparing shapes of different areas, then using a non-standard unit to measure area, then working within the metric system by using the faces of base-ten blocks, and then determining an appropriate unit for a given object and measurement.

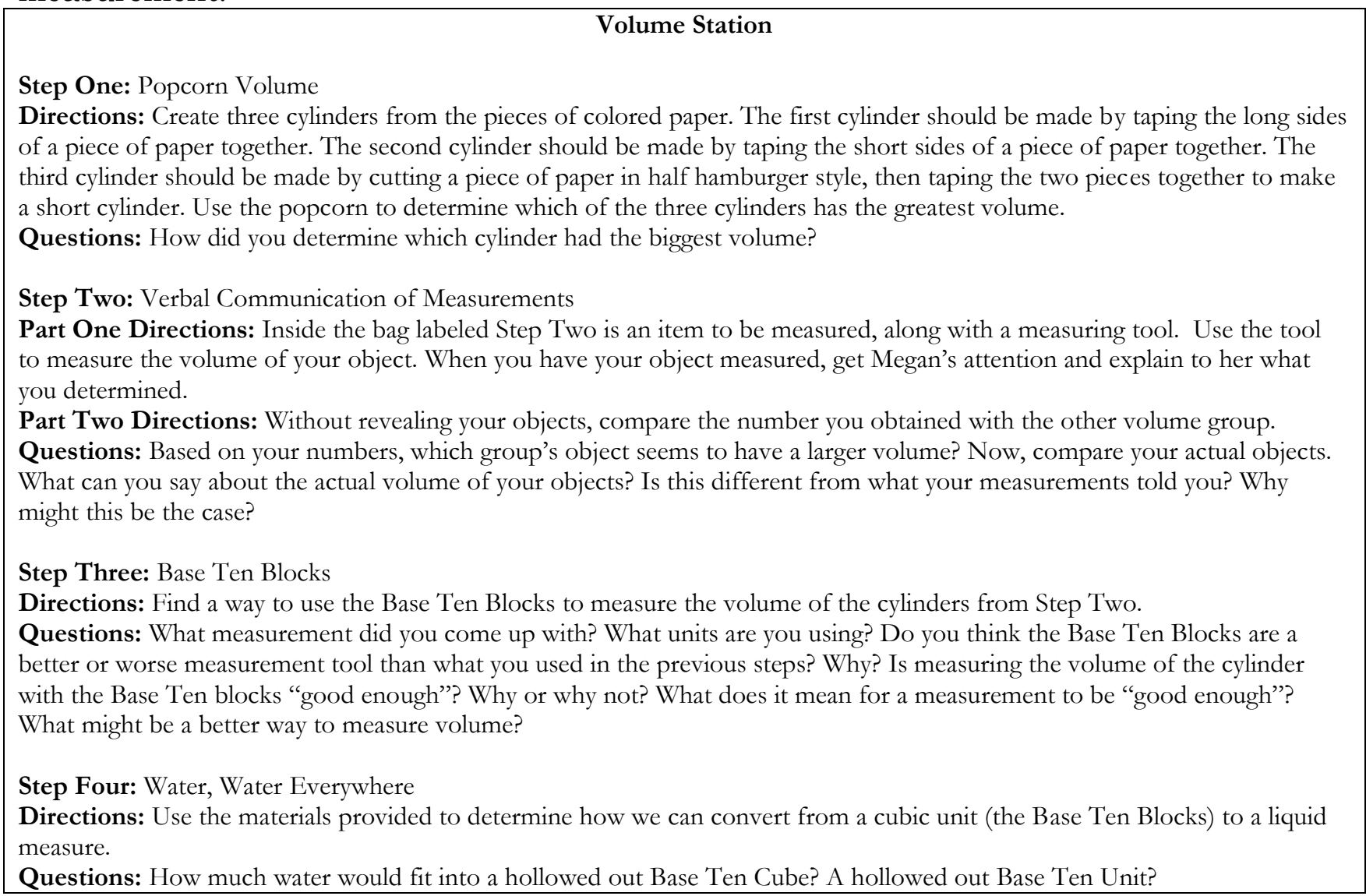

Figure 2. Volume station completed as part of the area and volume lesson 
Area Station

Step One: Which is the Largest?

Directions: Cut out the triangle, square, and circle. Determine some way (without using a ruler or similar measuring device) to verify which of the shapes has the largest area.

Questions: Which shape has the largest area? How do you know?

Step Two: Same as Volume Step Two but with area units and measurements.

Step Three: Area Treasure Hunt

Directions: We are going to use the faces of the Base Ten Blocks to measure area. Imagine spreading paint or ink on the faces and 'stamping' out the area when you approximate.

1. Use the Base Ten Blocks to measure (or estimate the measure of) the surface area of the following objects: a piece of paper, a CD case, a standard door, the bottom of a size seven shoe, a table top, and the top of a laptop.

2. For each of the following find or think of an object which fits the given area measurement and then explain your reasoning: ten square centimeters, one-hundred square centimeters, one square decimeter, three square decimeters, and one square meter.

Questions: Do you think the Base Ten Blocks are a better or worse measurement tool than the unit in Step Two? Why? How comfortable are you measuring area within the metric system?

Step Four: Guess the Unit

Directions: Try to guess what unit was used in each of the following measures:

1. The surface area of an average human fingernail is about 50

2. The area of a football field is about 50

3. The average surface area of a coffee table is about $85-90$

4. The surface area of a human palm is about 130

5. The surface area of a billboard is about 6

Figure 3. Area station completed as part of the area and volume lesson

After the prospective teachers completed their respective stations, each volume group presented their findings to an area group and vice-versa. For the presentation, the prospective teachers were directed to talk about how their attribute was measured, to describe the metric units used to measure their attribute, and to relate their activities to the Plan for Measurement Instruction. Finally, three post-assessments were given on both area and volume, a follow-up worksheet, a homework assignment, and an in-class exam (see Figures 4, 5, and 6).

\section{Area and Volume Follow-Up}

1. Which figure below has the bigger area? Why?
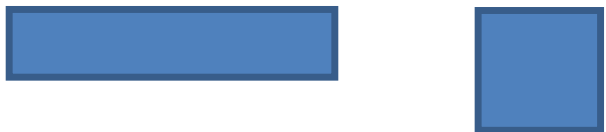

2. How would you go about proving which of the above shapes is bigger without using a measuring tool such as a ruler?

3. Which of the following shapes would be the best unit to use to measure volume? Why?
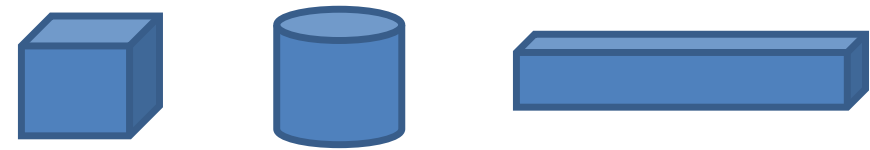

4. Explain why the volume of a shoebox is "length times width times height".

Figure 4. Area and Volume Follow-Up completed by the prospective teachers as a post-assessment 


\section{Homework}

1. Describe (using words and/or pictures) the following attributes: length, area, volume, time, mass, weight. Be extremely detailed!!

2. For the following groups of objects, do the following:

a. Determine the attribute (or attributes) being measured.

b. Give an example of appropriate English units for which you might measure the attribute.

c. Give an example of appropriate metric units for which you might measure the attribute.

d. Determine (if you can) an ordering from smallest to greatest. If you cannot give an order, explain why. (If more than one attribute is implied, give the order for both.)

\section{Group One}

The amount of wallpaper for a bedroom wall

The amount of sod for a football field

The amount of plastic wrap over a cake pan

\section{Group Two}

The amount of yarn used to make a scarf

The amount of hair cut off in a typical haircut

The amount of thread in a friendship bracelet

\section{Group Three}

The amount of matter in a piece of bread

The amount of water you drink in a day

The amount of food you eat in a day

\section{Group Four}

A handful of rabbit fur

A thimbleful of lead

A blown up balloon

\section{Group Five}

A tank of gas

A dose of cough medicine

A bottle of juice

\section{Group Six}

Pack for a week-long trip

Brush your teeth

Cook a turkey

\section{Group Seven}

How heavy a Christmas present is

How big a Christmas present is

How long it takes to open a present

Group Eight

The price of a new iPod

The price of a stick of gum

The price of a dinner at Panda Express

3. What is the area of the rectangle below? How do you know?

6

5

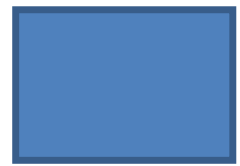

4. What is the area of the rectangle below? How do you know?

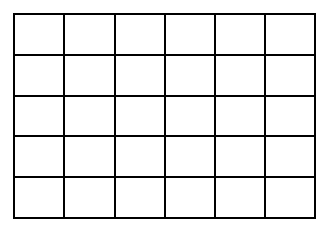

Figure 5. Homework assignment completed by prospective teachers as a second post-assessment

\section{Unit 1 Exam (exclusive to items relevant to area and volume)}

1. Describe the pros and cons of using each of the following as a unit for measuring area.
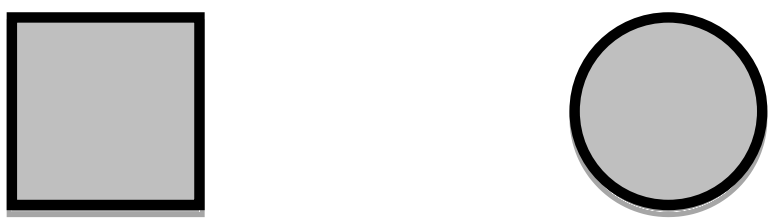

2. Order the following steps students commonly go through when learning measurement:

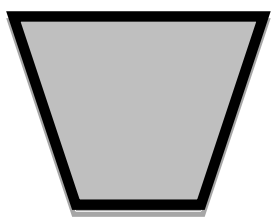

- _ Working within a standard measurement system

- Comparing objects with the same attribute

- _ Measuring with a non-standard unit

- _ Learning to perceive an attribute

- _ Measuring with a standard unit 
Which step of the measurement learning progression does the following activity address? (Explain your answer) A group of elementary students is asked to match the correct unit of length (centimeter, meter, kilometer, etc.) to various objects they might wish to measure, such as the distance from their house to the school, their height, etc.)

4. Identify the attribute being measured (choosing from length, area, volume, angle, mass, weight, or time) in each example below.

a. The circumference of a circle

b. The wallpaper needed to wallpaper a bedroom

c. The amount of thread used to sew on a button

d. The length of a movie

e. The amount of matter that makes up a dog

f. The amount of vaccine given to an infant

5. Imagine a box that is 10 centimeters wide, 8 centimeters long and 7 centimeters tall. We say the box has a volume of $10 \times 8 \times 7=560$. What are the units on this number?

6. Match the following measurements with the object they most likely measured:

d) a) one gram

b) two square-meters

c) one liter two kilometers

1. Volume of a base-ten cube

2. Length of a football field

3. Mass of a standard paper clip

4. Amount wallpaper to cover a classroom wall

5. Surface area of a standard door

6. Mass of a bottle of water

7. Distance from $3^{\text {rd }}$ street to $20^{\text {th }}$ street

8. Liquid in an extra-large jug of juice

7. Say the volume of an object is measured to be 1200. What does this number mean? (Don't just say it is the volume....)

Figure 6. Unit exam completed by prospective teachers as a third post-assessment

\section{Data Collection and Analysis}

Data were collected from 10 prospective teachers, five of whom completed the area station together as one group, and the other five of whom completed the volume station together as one group. The data sources included written work on the measurement preassessment, the area and volume stations, and the three post-assessments as well as audio recordings of the area and volume group.

Our analysis consisted of two phases. First, we conducted a 'real-time' analysis within the constraints of the week surrounding the actual lesson. The second author, the instructor, examined the prospective teachers' work on the pre-assessment and determined whether they would benefit more from the area or the volume station. Next, the first author listened to the audio recordings of the area and volume groups, creating a written document paraphrasing prospective teachers' actions and discussions. The second author listened through parts of the tapes as feasible with her schedule, making note of any adjustments to the written summary. Then, the first author produced a spreadsheet summarizing the prospective teachers' thinking on the follow-up worksheet. Each row represented one of the prospective teachers while each column represented a question from the assessment. Respective cells were used to summarize a prospective teacher's performance on a particular question. The last row was used to summarize across all prospective teachers their performance on the item. Finally, we engaged in various informal discussions, considering the prospective teachers' mathematical understandings, the impact of the activities and instruction, and ideas for future instruction.

The second phase of our analysis took place over the next several months, which we are referring to as 'intensive-delayed' analysis. For the volume station, we each individually relistened through the tapes several times, using a constant-comparative approach (Strauss $\&$ Corbin, 1998) to refine the associated written summary. Ultimately we arrived at a consensus summary that described the prospective teachers' discussions and mathematical understandings throughout the station as well as comments about how the instruction supported or sometimes hindered the prospective teachers' learning. We found the area group harder to interpret, as multiple ideas were being expressed by multiple group 
members at the same time. Thus, we listened through the tape together, working collaboratively to follow the various interpretations and note the group's eventual decisions and understandings. We then expanded the spreadsheet to include the pre-assessment, area and volume stations, follow-up worksheet, homework, and exam. Finally, together we examined the spreadsheet to prepare a summary of the prospective teachers' understandings with regard to each learning objective along with affordances and shortcomings of the instruction, including a listing of the adjustments we may make to this and future lessons.

\section{FINDINGS}

All 10 prospective teachers completed and turned in the pre-assessment and station activities; however, on each of the post-assessments, one student (a different student each time) did not turn in his/her work for various reasons.

\section{Pre-Assessment Results}

On the pre-assessment, only four prospective teachers described area as the amount of space a two-dimensional shape covers (K1). For example, Joshua explained area as "all of the space contained within the measurable part of an object (two-dimensional)." Other prospective teachers described area as length $x$ width (6 prospective teachers) or appeared to confuse area and volume (4 prospective teachers). None of the prospective teachers mentioned that area is measured by counting square units. When describing volume (K2), five prospective teachers described volume as "how much a three-dimensional object can hold". Three prospective teachers alluded to volume being an attribute of a threedimensional object but included language suggesting more of an area interpretation. Five prospective teachers wrote length $x$ width $x$ height in their explanation, while none of the prospective teachers explained that volume is measured in cubic units.

None of the prospective teachers selected area units for measuring volume objects or vice versa, although most of the prospective teachers did not select the appropriate measure and unit for a given object (S1 and $\mathrm{S} 2$ ). Only two prospective teachers successfully matched all the area and volume objects with their appropriate units and measures, while the other prospective teachers had limited success. The items that these prospective teachers tended to answer correctly involved units of very small or very large magnitude, e.g., kiloliters, milliliters. The pre-assessment did not assess learning objectives K3 or K4, as we initially thought that such objectives would be difficult to assess before addressing in class. In hindsight however, we feel this is possible. For example, we do not necessarily need to ask specifically about the Plan for Measurement Instruction (K4), but we could ask for ideas on how they would teach measurement to elementary students.

\section{Prospective Teachers' Work on the Volume and Area Stations}

Volume group. As the volume group began step one, they expected the volumes of the three cylinders to be equivalent since they were all created from the same size sheet of paper, e.g., the same lateral surface area. However, they were shocked to find:

By using our popcorn as a unit of measurement we determined that $\mathrm{C}$ had the biggest volume. When we filled A to the top the same amount of popcorn did not fill $\mathrm{B}$ and with the same amount again it only filled $\mathrm{C}$ to about half.

We suspect they were expecting a conservation-of-volume activity in which children are shown two objects (one taller and skinnier) with equivalent volume. Due to their surprise, the prospective teachers questioned the instructor about why the cylinders had different volumes. The instructor engaged them in a discussion of the cylinder volume formula $(V=$ $\left.\pi r^{2} h\right)$ and the greater impact of changes in the radius versus changes in the height. 
On step two, the prospective teachers used peanut butter cups to measure the volume of the second cylinder. They did so using the formula, e.g., finding the height and radius by measuring with the peanut butter cups and substituting into the formula. They determined a volume measurement of 39 peanut butter cups. They then decided to see how many cups would actually fit in the cylinder, resulting in 28 peanut butter cups. While waiting to share their measurement with the other volume group, they computed the volume by forming a layer of peanut butter cups on the bottom of the cylinder (4 cups fit) and then making stacks to match the height of the cylinder, leading to 32 peanut butter cups. To the instructor, they explained that they felt their first measurement was the most accurate because there would be no gaps between the peanut butter cups. Upon exchanging their measurements with another volume group, they realized that the different measurements resulted from the different sized units and that the size of a unit and the associated measurement are inversely related (the other volume group had used miniature peanut butter cups).

In step three, the prospective teachers used base-ten units to measure the volume of the second cylinder. Again, the prospective teachers used the volume formula to arrive at a measurement of approximately 500 cubic units. They discussed that the base-ten units were $1 \mathrm{~cm}$ by $1 \mathrm{~cm}$ by $1 \mathrm{~cm}$ and therefore agreed that the volume was $500 \mathrm{~cm}^{3}$. One student commented that he would be surprised if 500 base-ten units would fit in the cylinder, so the prospective teachers proceeded to place base-ten blocks in the cylinder, fitting in 430 base-ten units. They again recognized that there were gaps between the baseten units and therefore decided that $500 \mathrm{~cm}^{3}$ was a more reasonable measurement. In conclusion, they explained that while base-ten blocks are a better unit than the nonstandard unit of peanut butter cups, water may be the best unit for measuring volume since it eliminates gaps.

The prospective teachers began step four by filling the hollow base-ten cube with water from a $1 \mathrm{~L}$ bottle. As class time began to run out, the instructor visited the group. She clarified that the volume of the base-ten cube and the water bottle were the same. Therefore, $1000 \mathrm{~cm}^{3}$ is the same as $1 \mathrm{~L}$. She then asked how many milliliters are equivalent to the volume of $1 \mathrm{~cm}^{3}$. After helping the prospective teachers clarify that $1000 \mathrm{~mL}$ are in a liter, they collectively decided that $1 \mathrm{~cm}^{3}$ is equivalent in volume to $1 \mathrm{~mL}$.

Area group. On step one, the prospective teachers began by cutting out the shapes and laying them on top of each other. However, they did not consider how the overlapping components related to area. For example, upon placing the triangle over the circle, they found that the sides of the triangle extended over the edges of the circle, but they did not talk about whether the extended edges of the triangle would fit within the area of the circle. Therefore, they were more swayed by the side lengths and diameter than by the areas. Upon seeing the prospective teachers' cut-out shapes, the instructor asked them "Can I do anything with these to figure out which one fits inside?" The prospective teachers suggested cutting off the extended parts and seeing how they fit over the other shape. Upon doing so, the prospective teachers correctly ordered the shapes by area.

In step two, the prospective teachers measured the area of a rectangle using a nonstandard unit of square sticky-notes. They began by covering the rectangle with whole sticky-notes. For the remaining area, they cut off pieces of the sticky-notes, failing to record the fractional piece of each sticky-note. When counting the number of sticky-notes used, they had to backtrack and determine the fractional amount of the cut-up stickynotes. In this discussion, they recognized that the orientation and shape of the cut-out sticky-note did not matter, rather one just needed to determine what fraction it was of the original sticky-note. While they did not talk in these terms, they recognized that the areas of two shapes can be equal even if the two shapes are not congruent. Like in the volume station, upon sharing their measurements, units, and objects with another area group, the prospective teachers realized that the different units led to different measures and that the smaller measures indicated a larger unit was used (the other area group had larger sticky notes for their non-standard unit). 
The prospective teachers began step three by placing the base-ten units over a piece of paper and counting the number of base-ten units. They decided that the area of a piece of paper was " 588 ", with no mention of units. They then similarly found a reasonable estimate for the area of a CD case to be "168". To measure the surface area of a door, the prospective teachers decided to estimate the size of a standard door as the door in the classroom was excessively large (the classroom had very high ceilings). Furthermore, they decided to do this in terms of sheets of paper. Collectively, they decided that a standard door was approximately $7 \mathrm{ft}$ by $3.5 \mathrm{ft}$. Since a sheet of paper is 8.5 in. by 11 in., they decided that it would be approximately seven sheets to match the height of a standard door and approximately four sheets to match the width of a standard door (without maintaining the orientation of the paper). They then took 11 times 588, arriving at an unreasonable area measurement of " 6468 " $\mathrm{cm}^{2}$, which is equivalent to $0.6468 \mathrm{~m}^{2}$ and is too small for a standard door. It was not completely apparent from the audio-recording how the group arrived at the quantity 11 , but we suspect they may have added the height and width dimensions, e.g., seven sheets up plus four sheets across. The prospective teachers then proceeded to find reasonable estimates for the bottom of a size-7 shoe ("130") and for the top of a laptop (“735”).

When the prospective teachers began the second half of step three (finding objects with a given measure of area), the instructor visited the group. She helped them make explicit that the face of the base-ten unit was $1 \mathrm{~cm}^{2}$ because each side was exactly $1 \mathrm{~cm}$. One of the prospective teachers turned to the first given measure, $10 \mathrm{~cm}^{2}$, and asked, "Wouldn't 10 square centimeters be 100 though?" We suspect that he was interpreting the 10 as a linear measurement, meaning a $10 \mathrm{~cm}$ by $10 \mathrm{~cm}$ square so a flat with $100 \mathrm{~cm}^{2}$. The instructor picked up another flat and began counting square centimeters, pointing out that only the top row of the flat was $10 \mathrm{~cm}^{2}$. She then asked the prospective teachers how many square centimeters are in a flat, and they responded with 100. With the instructor's explication of the square centimeters, the prospective teachers then began to talk about the base-ten units and area measurements in terms of square centimeters.

The prospective teachers then began identifying objects for the given area measurements. They decided that because an eraser is approximately $2 \mathrm{~cm}$ by $5 \mathrm{~cm}$ that it has a top surface area of $10 \mathrm{~cm}^{2}$. They discussed whether an outlet might have a surface area of 100 $\mathrm{cm}^{2}$, determining it was about the size of a flat. Following some confusion about whether 1 $\mathrm{dm}^{2}$ is equivalent to a base-ten long or flat (some of the prospective teachers were again thinking linearly and using $1 \mathrm{dm}$ is $10 \mathrm{~cm}$ ), the prospective teachers decided $1 \mathrm{dm}^{2}$ is $1 \mathrm{dm}$ by $1 \mathrm{dm}$ so $100 \mathrm{~cm}^{2}$. As such, they reasonably selected the top of a common ramen noodle soup package. For $3 \mathrm{dm}^{2}$, the prospective teachers looked for an object that was approximately the size of 3 flats, ultimately selecting a half-sheet of paper. For $1 \mathrm{~m}^{2}$, the prospective teachers discussed that this would be $100 \mathrm{~cm}$ by $100 \mathrm{~cm}$ and therefore 10,000 $\mathrm{cm}^{2}$. After considering a few objects that they felt were too small, the prospective teachers began considering the very large door in the classroom. Without measuring the door, the prospective teachers decided the door was approximately $10 \mathrm{ft}$ by $3 \mathrm{ft}$, which they converted to meters by relating $1 \mathrm{~m}$ to $1 \mathrm{yd}$ so $3.5 \mathrm{~m}$ by $1 \mathrm{~m}$. They decided the door was $3.5 \mathrm{~m}^{2}$ and roughly $10,000 \mathrm{~cm}^{2}$. They failed to compare the original area measure, $1 \mathrm{~m}^{2}$, with their estimate of $3.5 \mathrm{~m}^{2}$. They appeared to visualize $1 \mathrm{~m}^{2}$ in terms of the $10,000 \mathrm{~cm}^{2}$ rather than as a $1 \mathrm{~m}$ by $1 \mathrm{~m}$ square. Furthermore, they did not discuss any conversions such as the number of square centimeters in $3.5 \mathrm{~m}^{2}$. At the end of step three, the prospective teachers wrote that "base-ten units are better because they are a standard unit of measure" and that they are "pretty comfortable" with measuring area in the metric system.

In guessing the units on area step four, the prospective teachers selected the unit between a unit that was clearly too large and a unit that was clearly too small. For example, to determine the unit for the area of a football field is about 50 _, the prospective teachers ruled out square kilometers as being too big (they related kilometers to miles) and then ruled out square meters as being too small, so they selected the unit of 
square decameters. This selection was made without thinking about the size of a square decameter and its relationship to the area of a football field. They appeared to understand the order of the metric units, e.g., millimeters are smaller than centimeters, are smaller than decimeters, are smaller than meters, etc. Throughout the step, they often said the linear unit, such as "millimeter" without saying that such units were squared for area. The prospective teachers did not appear to consider the given measurements, e.g., 50 for the football field, as the number of square units.

Presentations. The area group presented first to the volume group. In addition to describing their work above, they commented that circles do not work well as an area unit because gaps are left between them. For the Plan for Measurement Instruction, they said the activities were related to "being able to estimate and understand what the measurement is." Similarly for their presentation, the volume group described their work above, except they did not elaborate on how the formula helps explain why the cylinders have different volumes. Finally, they explained how their steps aligned with goal one of the Plan for Measurement Instruction, "Since seeing how much stuff would fit in each cylinder they [elementary students] would understand that the volume would be what is the space inside. Not the height and length which deals with area but the actual inside of it." Neither group commented on how the stations related to the later goals of the Plan for Measurement Instruction.

At the end of the presentations, the instructor asked the area group what they learned about volume. They stated that they learned volume is how much a three-dimensional object holds and that $1 \mathrm{~cm}^{3}$ is equivalent to $1 \mathrm{~mL}$. Similarly, she asked the volume group what they learned about area. They explained that it is better to measure area with a square unit than a circle unit. The instructor then asked them to describe area. Confusion arose amongst the prospective teachers about the difference between surface area, area, and volume. The instructor helped them clarify that volume is found by using all three dimensions of length, width, and height and that surface area and area are essentially the same (because both are measured in terms of square units). They also discussed the difficulties with seeing surface area and area as equivalent since the first typically is shown on a three-dimensional object and the second is shown on a two-dimensional object. Table 2 summarizes the prospective teachers' collective understandings after the stations and presentations.

Table 2. Prospective Teachers' Collective Understandings after the Stations and Presentations

Learning Objective Specific Topic Students Involved

K1: Area

K2: Volume

K4: Measurement
Instruction

S1: Measure area and volume
Area as the space covered by a two-dimensional object

Area is measured by counting square units

A square serves as the best area unit

Volume as how much a three-dimensional object can hold

Volume is measured by counting cubic units

Need a consistent unit and relation between unit size and measure

Recall goals in Plan

Match activities with each goal in Plan

Measure area and volume with non-standard units

Measure area and volume with standard units
All

All

All: Square units tessellate and circles leave gaps All

All: Volume is measured in cubic units, but liquid measures may better fill a container All

All: With first goal All: With first goal

All

Area group: By counting square units

Volume group: By counting cubic units and with formulas 
Match appropriate unit or measure with an object

S2: Units

Familiarity with standard units

Area group: Between a unit too
small and a unit too large
All: $\mathrm{cm}^{2}$ and $\mathrm{cm}^{3}$ and $1 \mathrm{~mL}$ is
equivalent to $1 \mathrm{~cm}^{3}$
Area group: More familiar with
extreme sized units and order of
metric units
Area group: Viewed area measures
more as linear quantities

of two linear measures

\section{Post-Assessment Results}

The post-assessments allowed us to learn about the understandings of the individual prospective teachers after the lesson. All prospective teachers described area as the amount of space a two-dimensional shape covers (K1), while only one student confused area and volume. Unfortunately, five prospective teachers continued to associate area with length $x$ width, failing to simultaneously acknowledge that this is a characteristic of rectangles only. It was challenging to determine whether the prospective teachers were trying to provide as much information as possible about area while knowing that the formula only applies to rectangles or whether the prospective teachers were equating area with length $x$ width. However, we are concerned about this as we feel many students (elementary and prospective teachers) tend to think of area as length $x$ width without seeing the broader definition of area.

Another component of $\mathrm{K} 1$ is recognizing that area is measured by counting square units. On the post-assessments, five prospective teachers explained this, with three more providing some evidence, and two others failing to mention the use of square units. To elaborate, Tina demonstrated a partial understanding. When asked to define area, she did not mention square units, but when given a rectangle with square units overlaid, she acknowledged that one could find the area by counting the square units. Results were mixed with regard to why a square is used for the area unit. When asked to describe the pros and cons of using a square, circle, or trapezoid to measure area (Exam \#1), six prospective teachers recognized that squares and trapezoids tessellate the plane, while seven prospective teachers realized that circles would leave gaps. Unfortunately, six prospective teachers felt that the best shape for an area unit depended on the shape of the object being measured. For example, Tina stated for a square, "The cons are that it's hard to use this unit to measure a circle or triangle because there would be space between some units." It appeared the prospective teachers wanted the area unit to line up with the edge of the shape being measured, possibly indicating a lack of understanding that gaps near the edge could be covered with another copy of the area unit and determining the fractional part used.

For learning objective K2, all prospective teachers explained that volume is the amount of space within a three-dimensional object. On the homework assignment, four prospective teachers included length $x$ width $x$ height when explaining volume, again raising concerns. Four prospective teachers revealed an understanding of using cubic units; as Nichole explained, "Volume is measured in units cubed." On \#3 from the follow-up assessment, six prospective teachers selected the cube as the best volume unit (two prospective teachers misinterpreted this item, thinking they were to find the volume of the provided objects). Two prospective teachers acknowledged that cylinders will leave gaps, one student explained that the rectangular prism could work but that its dimensions are not equal, and one student said that theoretically all three objects could work because they are all threedimensional. On \#4 of the follow-up assessment, six prospective teachers explained that we need to multiply by height as well as length times width because we are working with a three-dimensional object. Donna explained, “Because you don't want just area of one side, 
you want a 3D shape. The height adds another dimension." In conclusion, it appeared most of the prospective teachers understood that volume is measured in cubic units.

We felt prospective teachers fully understood K3, so it was only assessed within the area and volume stations. With regard to learning objective $\mathrm{K} 4$, all prospective teachers correctly completed \#2 on the exam, indicating at least a recall level of the steps in the Plan for Measurement Instruction. On \#3, all prospective teachers recognized that the activity involved working within a measurement system and selecting an appropriate unit for the magnitude of different objects. In conclusion, we felt the prospective teachers could order the various steps in the learning progression, although we are uncertain of the depth of their understanding. For example, could they identify or generate activities for the various goals? Did they understand the need for sequencing instruction in this fashion?

One component of S1 is being able to measure area or volume without a standard measuring tool. On \#1 and \#2 from the follow-up post-assessment, prospective teachers were asked to do so for area. Four prospective teachers explained that they would cut the shapes out and place them on top of each other. Two prospective teachers each described each of the following other approaches: Compare the areas by covering the two shapes with a non-standard unit, by relating the two sets of dimensions, or by comparing the number of square units inside each. Respectively, Donna commented, "By taking something like sticky-notes and seeing how many can fit." Mallory wrote, ". . . the length of one [the rectangle] is a little more than twice that of 2 [the square], while the width of 2 is only twice that of 1 . Therefore 1 must have more area." Finally, Nichole explained, "I split the shape into equal units [she drew square units on the two shapes] and then compared area."

Another component of S1 involves selecting an appropriate unit. First, one has to select a unit that matches the attribute to be measured, e.g., an area unit for measuring area and a volume unit for measuring volume. Matching the unit with the intended attribute was successfully completed by the prospective teachers throughout the post-assessments. Second, selecting an appropriate unit requires determining a unit of an appropriate magnitude, which often includes considering the size of the unit and the associated measurement. On homework problem \#2, it was challenging to determine prospective teachers' understanding in this regard because it was not clear in the directions that the prospective teachers were to provide an appropriate unit for every object in a set. However, four prospective teachers did offer such units and upon doing so, selected appropriatelysized units. In conclusion, we suspect that approximately half of the prospective teachers were able to select an appropriate unit and measure, while more prospective teachers were capable of doing so when units of an extreme size were appropriate (similar to results from the stations).

Learning objective S2 states that prospective teachers will develop familiarity with standard units for area and volume. This includes visualizing the size of area and volume units. On test item \#6, all prospective teachers were able to match $2 \mathrm{~m}^{2}$ with the surface area of a standard door. For the unit of $1 \mathrm{~L}$, three prospective teachers correctly selected the volume of a base-ten cube, four prospective teachers selected the liquid in an extralarge jug of juice (not too unreasonable, but we were envisioning a jug that holds more like 4-5 L), and two prospective teachers selected the mass of a bottle of water. Overall, the prospective teachers gained some familiarity with the area and volume standard units, especially square centimeters and cubic centimeters, but it is difficult to assess their familiarity with the other standard units as we realized after the fact that it would have been helpful to include more post-assessments items for this learning objective. Table 3 summarizes the individual prospective teachers' understandings from the pre-assessment to the post-assessments. 
Table 3. Prospective Teachers Understandings across the Lesson Experiment

\begin{tabular}{|c|c|c|c|c|}
\hline Learning Objective & Specific Topic & $\begin{array}{r}\text { Pre- } \\
n\end{array}$ & $\begin{array}{r}\text { Post- } \\
n\end{array}$ & $\begin{array}{l}\text { Trend from Pre- to Post- } \\
\text { Assessment }\end{array}$ \\
\hline \multirow[t]{7}{*}{ K1: Area } & $\begin{array}{l}\text { Area as the space covered by a two- } \\
\text { dimensional object }\end{array}$ & 4 & All & Improvement \\
\hline & Equated area with length $\times$ width & 6 & 5 & $\begin{array}{l}\text { Fairly static; many of the } \\
\text { same students }\end{array}$ \\
\hline & Confused area and volume & 4 & 1 & Improvement \\
\hline & Area is measured by counting square units & 0 & 8 & Improvement \\
\hline & Squares and trapezoids tessellate the plane & --- & 6 & $\begin{array}{l}\text { Perhaps prior knowledge or } \\
\text { improvement }\end{array}$ \\
\hline & Circles leave gaps & --- & 7 & $\begin{array}{l}\text { Perhaps prior knowledge or } \\
\text { improvement }\end{array}$ \\
\hline & $\begin{array}{l}\text { Best shape for unit depends on shape of } \\
\text { object being measured }\end{array}$ & --- & 6 & Interpretation to address \\
\hline \multirow[t]{4}{*}{ K2: Volume } & $\begin{array}{l}\text { Volume as how much a three-dimensional } \\
\text { object can hold }\end{array}$ & 5 & All & Improvement \\
\hline & $\begin{array}{l}\text { Associated volume with three-dimensions } \\
\text { but used area language }\end{array}$ & 3 & None & $\begin{array}{l}\text { Improvement or } \\
\text { communication }\end{array}$ \\
\hline & Equated volume with length $\times$ width $\times$ height & 5 & 4 & $\begin{array}{l}\text { Fairly static; many of the } \\
\text { same students }\end{array}$ \\
\hline & $\begin{array}{l}\text { Volume is measured by counting cubic } \\
\text { units }\end{array}$ & 0 & 8 & $\begin{array}{l}\text { Improvement or } \\
\text { communication }\end{array}$ \\
\hline K3: Consistent unit & $\begin{array}{l}\text { Need a consistent unit for consistent } \\
\text { measures; small units lead to larger } \\
\text { measurements and vice versa }\end{array}$ & --- & --- & $\begin{array}{l}\text { Perhaps prior knowledge or } \\
\text { improvement }\end{array}$ \\
\hline \multirow{2}{*}{$\begin{array}{l}\text { K4: Measurement } \\
\text { Instruction }\end{array}$} & Recall goals in Plan & --- & All & Possible improvement \\
\hline & Match activities with each goal in Plan & --- & All & Possible improvement \\
\hline \multirow[t]{3}{*}{$\begin{array}{l}\text { S1: Measure area } \\
\text { and volume }\end{array}$} & Measure area with non-standard units & --- & All & $\begin{array}{l}\text { Perhaps prior knowledge or } \\
\text { improvement }\end{array}$ \\
\hline & $\begin{array}{l}\text { Select area units for area and volume units } \\
\text { for volume }\end{array}$ & All & All & Prior knowledge \\
\hline & $\begin{array}{l}\text { Match appropriate unit or measure with an } \\
\text { object }\end{array}$ & 2 & 4 & Some improvement \\
\hline S2: Units & Familiarity with standard units & 2 & All & Some improvement \\
\hline
\end{tabular}

\section{Impact of Instruction}

Overall, the lesson provided several benefits for prospective teachers' learning. First, as recommended for K-12 students (NCTM, 2000), the activities provided concrete and active experiences in finding, comparing, and exploring area and volume. This active process contributed to prospective teachers' understanding of area as coverage and volume as filling. Second, given that the Plan for Measurement Instruction is helpful for learners of all ages, the stations led prospective teachers through the Plan for Measurement Instruction. Third, the lesson met the prospective teachers' needs in area and volume since it was differentiated by their performance on the pre-assessment. Finally, the lesson allowed the prospective teachers to learn from each other through group work and presentations. We describe next the affordances, shortcomings, and possible adjustments for the volume and area stations.

Impact of volume station. Step one allowed prospective teachers to experience volume as 'filling' a three-dimensional object. In addition, using three cylinders from the same size sheet of paper helped prospective teachers appreciate the relationship between surface area and volume and provided an example of different volumes resulting from equivalent surface 
areas, in contrast to typical examples for the conservation of volume. Step two made explicit that different units yield different measurements and that smaller units lead to larger measurements and vice versa. In addition, since the prospective teachers were free to use a measuring process of their choice, they measured the cylinder in several ways, with the formula, by placing units in the cylinder, and by thinking about stacking rows of the base. As step one and two met our intended learning objectives, we do not recommend any adjustments to these steps.

Physically enacting step three allowed the prospective teachers to gain familiarity with the size of a cubic centimeter and to experience the advantages of measuring volume with standard cubic units. This in combination with step two helped prospective teachers appreciate using liquid units, which "fill all the gaps". Also similar to step two, prospective teachers were free to measure in different ways, leading them to compare their results and have rich discussions about precision and more effective volume units. However, we realized that this step was limited to cubic centimeters. In particular, it did not assist prospective teachers with examining the size of a cubic decimeter and its relationship to a cubic centimeter. Establishing this relationship may have assisted prospective teachers with recognizing in step four that $1000 \mathrm{~cm}^{3}$ make up $1 \mathrm{~L}$ and therefore $1 \mathrm{~cm}^{3}$ is equivalent to $1 \mathrm{~mL}$. In future implementations of step three, we recommend directing prospective teachers to measure the cylinder in base-ten units and then in base-ten cubes (cubic decimeters) while asking them to consider and articulate the relationship between the two.

In step four, by emptying the contents of a $1 \mathrm{~L}$ bottle into a base-ten cube, most of the prospective teachers realized that $1 \mathrm{~L}$ is equivalent to $1 \mathrm{dm}^{3}$ and that $1 \mathrm{~cm}^{3}$ is equivalent to $1 \mathrm{~mL}$. A shortcoming of this step was that it did not help prospective teachers gain familiarity with other volume units, e.g., cubic inch, cubic foot, cubic meter, etc. To do so, we would revise this step to include opportunities for prospective teachers to physically represent these other volume units, to measure the volume of various objects with these units, to identify objects with a given volume in terms of these units, and to guess the unit for given objects and volume measurements (similar to step three and four of the area station).

Impact of area station. An affordance of step one was that if one attended to the linear dimensions rather than the area dimensions, then one would rank the shapes incorrectly. Indeed, this allowed the instructor to realize that the group was doing so and encourage them to focus their attention more so on area. However, if the instructor had not visited the group at this opportune time, their thinking may not have been challenged. Thus, we would revise this step to direct prospective teachers to physically justify their ranking of the shapes by area.

Similar to the second step of the volume station, step two of the area station made explicit the need for a consistent unit and the inverse relationship between the size of a unit and a measurement. In addition, because prospective teachers had to cut the sticky-notes to cover the rectangle, the idea arose that different shapes may have the same area. The instructor built on this idea in a successive lesson by using geo-boards to investigate the area of triangles and parallelograms which had the same base and altitude (and thus the same area) but looked very different. In the future, it may be helpful to use an irregular shape rather than a rectangle in the area station, which may highlight area as the coverage of a two-dimensional shape and the need to take fractional parts of units. In addition, since this step provided prospective teachers with a square non-standard unit, it did not bring out the need to use area units that tessellate the plane and the convenience of using a square unit (beyond noting that a circle unit leaves gaps). For future implementations, perhaps a step should be inserted between step one and two where prospective teachers may be asked to measure the area of various objects with different shaped units, e.g., a triangle unit, a trapezoid unit, an irregular unit, etc. For each, prospective teachers could be asked to consider advantages and disadvantages of using that shape as an area unit. This may address prospective teachers' preferences to select a shape for an area unit depending on the object being measured. 
The first half of step three directed prospective teachers to measure various objects with base-ten units. Doing so helped the prospective teachers think about measuring area in terms of square units and the value of a standard unit. However, the directions may be enhanced by specifying that the face of each base-ten unit is $1 \mathrm{~cm}$ by $1 \mathrm{~cm}$ to facilitate the language of using units of size $1 \mathrm{~cm}^{2}$. In addition, the unexpected complexity of measuring the very large door in the classroom reiterated to us the importance of prospective teachers physically measuring the objects to check their calculations.

On the second half of step three, identifying objects for a given area measurement revealed the confusion some prospective teachers had about these (e.g., is $10 \mathrm{~cm}^{2}$ the size of a base-ten long or of a base-ten flat?). We feel that such confusions may not have arisen had we concluded with only measuring given objects. Through group discussion and interactions with the instructor, some of these confusions were addressed. Another possibility is to specifically ask prospective teachers to discuss the similarities and differences between a '10 centimeter square' and '10 square centimeters' and which one aligns with $10 \mathrm{~cm}^{\wedge} 2$. Another shortcoming of the step was that finding objects for a given area measurement presupposed that the prospective teachers already had familiarity with the size and shape of several standard area units, e.g., square decimeter, square meter, etc. We recommend restructuring this step as follows. First, ask prospective teachers to build the various standard area units. For example, ask them to draw $1 \mathrm{~cm}^{2}$ or to use masking tape to mark off $1 \mathrm{~m}^{2}$. Then, ask prospective teachers to compare these units with the base-ten blocks so that they may understand how to use the base-ten units as a measuring tool for area. In addition, ask the prospective teachers to identify objects that have sizes approximately equal to these standard area units and thereby develop personal benchmarks. Finally, ask the prospective teachers to measure multiple objects using an appropriate unit and to identify objects for a given area measurement. This sequence may provide prospective teachers with more familiarity with the standard area units and help them understand for example that a square meter is $1 \mathrm{~m}$ by $1 \mathrm{~m}$. Both of which would likely better prepare prospective teachers for step four.

An affordance of step four was assisting prospective teachers with understanding the order and comparative magnitude of the various metric units. Unfortunately, in determining the missing units, the prospective teachers tended to think in linear terms. For example, prospective teachers interpreted the 90 square units for the coffee table as 90 linear units rather than the number of square units resulting from two linear measurements that multiply to 90 . The revisions to step three described above may assist with this, but we would also add some precursor questions to step four, such as "Use the base-ten blocks or a scale drawing to illustrate 6 square decimeters $\left(6 \mathrm{dm}^{2}\right)$." We hope this would assist prospective teachers with realizing that $6 \mathrm{dm}^{2}$ consists of six squares, which could be arranged in various ways if one chooses to use a rectangle, e.g. $2 \mathrm{dm}$ by $3 \mathrm{dm}$ or 6 $\mathrm{dm}$ by $1 \mathrm{dm}$.

The group presentations yielded some affordances but also had some shortcomings. They allowed the prospective teachers to learn from one another about the other attribute in an efficient fashion, e.g., we did not need to have every student complete both the area and volume station. However, the prospective teachers did not articulate the connections between the stations and the goals in the Plan for Measurement Instruction. We have two possible adjustments for this. First, revise the directions for the presentation to explicitly direct the prospective teachers to align the steps in the stations with the goals in the Plan for Measurement Instruction. Second, have a follow-up activity in which prospective teachers align various measurement activities with the Plan for Measurement Instruction. Indeed, the instructor facilitated such a lesson in her class a few days after the area and volume lesson.

Refinements to post-assessments and learning objectives. Our analysis also generated refinements to the post-assessments. On \#2 of the homework, we would clarify that prospective teachers should select a metric and English unit for every object in a set. 
Also on the homework assignment, we would ask prospective teachers to relate their work on \#3 and \#4. This may provide further information about whether prospective teachers realized area is measured in square units and the connection between length $x$ width and the number of square units. On \#1 from the exam, asking prospective teachers to provide pros and cons for each shape may have led them to provide both despite the fact that some shapes did not have a pro or did not have a con. Thus, we would revise this item to state that they should rank the shapes according to the best unit for area or that they do not necessarily have to provide pros and cons for every shape. Finally, for learning objectives $\mathrm{K} 4$ and S2 we would include more items on the post-assessment. Also for K4, none of our assessment items evaluated the prospective teachers' understandings of the need for sequencing instruction as recommended in the Plan for Measurement Instruction.

Finally, our instructional experiences and analysis provided feedback on our original learning objectives. In real-time, we strove to assess our various learning objectives on all of our assessments, but in hindsight realized that the phrasing of our original learning objectives may have hindered this a bit. Specifically, some finer gradation of our objectives may have helped. For example, we are considering splitting S1 by attribute, either area or volume, as well as perhaps delineating between some of the sub-topics that emerged as aspects of the overall learning objectives (see Table 3, column 2).

\section{CONCLUSIONS AND DISCUSSION}

The purpose of this study was to investigate how instruction impacts the understandings of prospective teachers enrolled in a mathematics content course. Specifically, we used a lesson experiment to examine how an area and volume lesson impacted prospective teachers' associated understandings. Much information emerged about prospective teachers' understandings of area and volume and how such understandings were impacted by this specific lesson. Without the lesson experiment approach, we doubt that we would have recognized these ideas about instruction and understanding.

The lesson experiment confirmed that prospective teachers may enter their mathematics courses without some essential understandings about area and volume (Enochs \& Gabel, 1984). A significant number of our prospective teachers began the course with limited understandings of area and volume, how they are measured, and their standard metric units. Fortunately, the lesson experiment also demonstrated that engaging the prospective teachers in physical activities of measuring area and volume fairly quickly enhanced their understandings, including seeing area as 'coverage', recognizing volume as 'filling', realizing that different units lead to different measurements, and learning how to compare area and volume without standard measuring tools.

We also saw again through the lesson experiment how pervasive formulaic understanding can be (Baturo \& Nason, 1996; Enochs \& Gabels, 1984; Saiz, 2003; Tierney, Boyd, \& Davis, 1990) as well as the drawbacks of teaching students about measurement formulas before they understand attributes and how they are measured. Even after our lesson, approximately half of the prospective teachers still associated area with length $x$ width and volume with length $x$ width $x$ height. Furthermore, some prospective teachers when defining area and volume failed to mention that area is measured in square units and volume in cubic units. Hopefully, our recommended adjustments to the lesson may help address these issues.

The lesson experiment also revealed new findings with regard to prospective teachers' understandings of area and volume. First was the realization that many of the prospective teachers tended to believe that the best area or volume unit depended on the object being measured, e.g., a unit with curved sides is better for measuring the area of a curved shape. As a result, we recommend providing prospective teachers with opportunities to investigate the use of different shapes for area units or volume units and thereby derive that square units are best for area and cubic units are best for volume. Another critical realization was the importance of not only asking prospective teachers to measure particular objects with 
given standard units, but to identify objects with a given measurement, e.g., find an object with a top surface area of $10 \mathrm{~cm}^{2}$. This additional challenge revealed uncertainties and misconceptions in the prospective teachers' thinking. Specifically, prospective teachers tended to interpret area and volume measurements as linear quantities (Reinke, 1997; Zevenbergen, 2005) and failed to recognize for example that $1 \mathrm{~m}^{2}$ is equivalent to a $1 \mathrm{~m}$ by 1 $\mathrm{m}$ square. We feel delineating the prospective teachers' thinking in this manner greatly assisted us in thinking about how to revise the stations. Finally, we suspect that it may be equally important that prospective teachers understand why elementary students need to progress through the Plan for Measurement as well as being able to articulate the different steps. Without an appreciation for this sequencing, prospective teachers likely will not incorporate the progression in their own teaching. In future implementations of this lesson, we would recommend incorporating discussions and activities that would help prospective teachers understand the need for the sequence, not just understanding the various goals.

In reflecting on conducting a lesson experiment, we made some important realizations about our analysis procedures. As explained in the Methods section, our analysis consisted of two phases, a real-time analysis and an intensive-delayed analysis. The real-time analysis proved helpful in at least three ways. First, we were able to respond to the prospective teachers' recognition that different shapes may have the same area and offer a follow-up lesson investigating the area of triangles and parallelograms with equivalent areas. Second, due to the unforeseen complexity of using units with varying dimensions, a successive lesson was taught in which prospective teachers cut out nets of cubes and of rectangular prisms and discussed which of the two would serve as a better unit for volume. Finally, due to the prospective teachers' failure to mention the later goals of the Plan for Measurement Instruction, the instructor incorporated a follow-up activity in which the prospective teachers sorted elementary mathematical tasks by goals in the Plan for Measurement Instruction.

Despite these advantages, we feel the power of the lesson experiment came from our intensive-delayed analysis. In initially reading Hiebert, Morris, and Glass (2003) and Hiebert, Morris, Berk, and Jansen (2007), we envisioned the analysis phase of a lesson experiment being completed relatively close to the implementation of the lesson. Whether this was the authors' intention, we want to highlight the value we found in the intensivedelayed analysis. It was this analysis that allowed us to much more specifically describe the prospective teachers' mathematical thinking and how it was impacted by the instruction.

In closing, Hiebert, Morris, and Glass (2003) state,

Teacher educators lack a shared knowledge base for building more effective teacher preparation programs. Teacher colleges and universities might learn from each other about program features and requirements, but little shared information is at the instructional level and even less is supported by research on effectiveness. (p. 202)

They propose that sharing the lessons created from lesson experiments may serve as one way to contribute to the knowledge base for teacher educators. We hope our lesson and descriptions of prospective teachers' mathematical thinking about area and volume will serve as one step in this direction, while possible replications of this lesson experiment may serve as even further steps. Throughout this first iteration, we found lesson experiments to provide a meaningful avenue for connecting research and practice. Specifically, we were engaging in two roles: researchers in teacher education and teachers of mathematics content. Due to the collection of research data, we enhanced our interpretations of the prospective teachers' thinking which thereby enhanced our future instruction. Similarly, our instructional roles provided insight into the prospective teachers' activities and experiences during class, enhancing our ability to hypothesize how the instruction was impacting the prospective teachers' understandings. In sum, the lesson experiment process helped reveal hypotheses about how the instruction was impacting the prospective teachers' learning and mathematical understandings - the primary purpose of our project. 


\section{REFERENCES}

Baturo, A., \& Nason, R. (1996). Student teachers subject matter knowledge within the domain of area measurement. Educational Studies in Mathematics, 31(3), 235-268. doi: 10.1007/BF00376322

Berenson, S., Van Der Valk, T. M., Oldham, E., Runesson, U., Moreira, C. Q., \& Broekman, H. (1997). An international study to investigate prospective teachers' content knowledge of the area concept. European Journal of Teacher Education, 20(2), 137150. doi: 10.1080/0261976970200203

Buck, R. E. (2004). Expanding mathematics preparation of elementary and middle school teachers. Primus: Problems, Resources, and Issues in Mathematics Undergraduate Studies, 14(2), 141-155. doi: 10.1080/10511970408984082

Chamberlin, M. T., \& Powers, R. A. (2010). The promise of differentiated instruction for enhancing the mathematical understandings of college students. Teaching Mathematics and Its Applications: An International Journal of The Institute of Mathematics and Its Applications, 29(3), 113-139. doi: 10.1093/teamat/hrq009

Clarke, D. (1997). A compulsory mathematics unit for elementary preservice teachers: Content, pedagogy and assessment. Annual Conference of the Association of Mathematics Teacher Educators, Washington, DC.

Conference Board of the Mathematical Sciences (CBMS). (2001). The mathematical education of teachers. Washington, D.C.: Mathematical Association of America (MAA) in cooperation with American Mathematical Society (AMS).

Crespo, S., \& Nicol, C. (2006). Challenging preservice teachers' mathematical understanding: The case of division by zero. School Science and Mathematics, 106(2), 8497. doi: 10.1111/j.19498594.2006.tb18138.x

Delaney, S., Ball, D. L., Hill, H. C., Schilling, S. G., \& Zopf, D. (2008). Mathematical knowledge for teaching. Journal of Mathematics Teacher Education, 11, 171197. doi: 10.1007/s 10857-008-9072-1

Enochs, L. G., \& Gabel, D. L. (1984). Preservice elementary teachers' conceptions of volume. School Science and Mathematics, 84(8), 670$680 . \quad$ doi: 10.1111/j.19498594.1984.tb09582.x

Hart, L. C. (2002). Preservice teachers' beliefs and practice after participating in an integrated content/methods course. School Science and Mathematics, 102(1), 4-14.
Hiebert, J., Morris, A., K., Berk, D., \& Jansen, A. (2007). Preparing teachers to learn from teaching. Journal of Teacher Education, 58(1), 47-61. doi: $10.1177 / 0022487106295726$

Hiebert, J., Morris, A. K., \& Glass, B. (2003). Learning to learn to teach: An "experiment" model for teaching and teacher preparation in mathematics. Journal of Mathematics Teacher Education, 6, 201-222.

Inskeep, J. E. (1976). Teaching measurement to elementary children. National Council of Teachers of Mathematics Yearbook (pp. 6086). Reston, VA: National Council of Teachers of Mathematics.

Lester, F. K., Jr., et al. (1992). Preparing elementary teachers to teach mathematics (PETTM): A problem-solving approach. (Final Report. Volume II: Content Component). Bloomington, IN: Indiana University, Mathematics Education Development Center.

Libeskind, S. (2011). Teaching mathematics for prospective elementary school teachers: What textbooks don't tell. Primus: Problems, Resources, and Issues in Mathematics Undergraduate Studies, 21(5), 473-484. doi: $10.1080 / 10511970903296106$

Lubinski, C. A., \& Otto, A. D. (2004). Preparing $\mathrm{K}-8$ preservice teachers in a content course for standards-based mathematics pedagogy. School Science and Mathematics, 104(7), 336-336. doi: 10.1111/j.19498594.2004.tb18252.x

Matthews, M., Rech, J., \& Grandgenett, N. (2010). The impact of content courses on pre-service elementary teachers' mathematical content knowledge. Issues in the Undergraduate Mathematics Preparation of School Teachers: The Journal, 1, Retrieved from http://www.k12prep.math.ttu.edu/journal/contentknowl edge/rech01/article.pdf

Matthews, M. E., \& Seaman, W. I. (2007). The effects of different undergraduate mathematics courses on the content knowledge and attitude towards mathematics of preservice elementary teachers. Issues in the Undergraduate Mathematics Preparation of School Teachers: The Journal, 1, Retrieved from http://www.k-

12prep.math.ttu.edu/journal/contentknowl edge/matthews01/article.pdf

McLeod, K., \& Huinker, D. (2007). University of Wisconsin-Milwaukee mathematics focus courses: Mathematics content for 
elementary and middle grades teachers. International Journal of Mathematical Education in Science and Technology, 38(7), 949-962.

doi: $10.1080 / 00207390701579498$

Mewborn, D. S. (2001). Teachers' content knowledge, teacher education, and their effects on the preparation of elementary teachers in the United States. Mathematics Teacher Education and Development 3, 2836.

Mizell, J. A., \& Cates, J. (2004). The impact of additional content courses on teacher candidates beliefs regarding mathematics content and pedagogy. Issues in the Undergraduate Mathematics Preparation of School Teachers: The Journal, 4, Retrieved from http://www.eric.ed.gov/PDFS/EJ835512.p df

Murphy, C. (2012). The role of subject knowledge in primary prospective teachers' approaches to teaching the topic of area. Journal of Mathematics Teacher Education, 15(3), 187206. doi: $10.1007 / \mathrm{s} 10857-011-9194-8$

National Commission on Mathematics and Science Teaching for the Twenty-First Century. (2000). Before it's too late: A report to the nation. Jessup, MD: U.S. Department of Education. Retrieved from http://www.nationalmathandscience.org/si tes/default/files/resource/before\%20its $\% 20$ too\%20late.pdf

National Council of Teachers of Mathematics. (2000). Principles and standards for school mathematics. Reston, VA: Author.

National Council of Teachers of Mathematics. (2007). Mathematics teaching today. Reston, VA: Author.

National Governors Association Center for Best Practices \& Council of Chief State School Officers. (2010). Common core state standards for mathematics. Washington, D.C.: Authors. Retrieved from http://www.corestandards.org

National Mathematics Advisory Panel. (2008). Foundations for success: The final report of the National Mathematics Advisory Panel. Washington, D.C.: U.S. Department of Education.

National Research Council. (2001). Adding it up: Helping children learn mathematics. Washington, DC: National Academy Press.

O'Keefe, M., \& Bobis, J. (2008). Primary teachers' perceptions of their knowledge and understanding of measurement. In M. Goos, R. Brown, \& K. Makar (Eds.), Navigating Currents and Charting Directions (Proceedings of the 31st Annual Conference of the Mathematics Education Research Group of Australasia) (pp. 391-398). Brisbane, Australia: Mathematics Education Research Group of Australasia.

Quinn, B., \& Jadav, A.D. (1987). Causal relationship between attitude and achievement for elementary grade mathematics and reading. Journal of Educational Research, 80(6), 366-372.

Reinke, K. S. (1997). Area and perimeter: Preservice teachers' confusion. School Science and Mathematics, 97(2), 75-77.

Saiz, M. (2003). Primary teachers' conceptions about the concept of volume: The case of volume-measurable objects. Proceedings of the 27th International Group for the Psychology of Mathematics Education (pp. 95-102). Honolulu, HI: International Group for the Psychology of Mathematics Education.

Senk, S., Demir, M., Park, J., \& Crespo, S. (2009). Pre-service elementary teachers knowledge of geometry and measurement. In S. L. Swars, D. W. Stinson, \& S. LemonsSmith (Eds.), Proceedings of the 31st Annual Meeting of the North American Chapter of the International Group for the Psychology of Mathematics Education (pp. 569-576). Atlanta, GA: Georgia State University.

Sowder, J., Sowder, L., \& Nickerson, S. (2009). Reconceptualizing mathematics for elementary school teachers. New York, NY: W. H. Freeman.

Strauss, A., \& Corbin, J. (1998). Basics of qualitative research: Techniques and procedures for developing grounded theory ( $2^{\text {nd }}$ ed.). London: Sage.

Tierney, C., Boyd, C., \& Davis, G. (1990). Prospective primary teachers' conceptions of area. In G. Booker, P. Cobb, \& T. D. Mendecuti (Eds.), Proceedings of the 14th Annual Conference of the International Group for the Psychology of Mathematics Education (pp. 307-315). Mexico: International Group for the Psychology of Mathematics Education.

Van de Walle, J. A., \& Lovin, L. H. (2006). Teaching student-centered mathematics: Grades K-3. Columbus, OH: Allyn \& Bacon.

Wiggins, G., \& McTighe, J. (2005). Understanding by design (2 $2^{\text {nd }}$ ed.). Alexandria, VA: Association for Supervision and Curriculum Development.

Woodward, E., \& Byrd, F. (1983). Area: Included topic, neglected concept. School Science and Mathematics, 83(4), 343-347. doi: 10.1111/j.1949-8594.1983.tb10119.x

Zevenbergen, R. (2005). Primary pre-service teachers' understandings of volume: The 
M. Chamberlin, M. S. Candelaria

impact of course and practicum

experiences. Mathematics Education

Research Journal, 17(1), 3-23. doi:

10.1111/j.1949-8594.1983.tb10119.x

$\diamond \diamond \diamond$

Citation Suggestions :

APA : Chamberlin, M., \& Candelaria, M. S. (2014). Investigating area and volume instruction for prospective teachers: A lesson experiment. Mathematics Education, 9(2), 113-134. 